Zrinka Karačića, Jasminka Špoljarića ${ }^{a}$, Marko Rožman and Marija Abramić*

\title{
Molecular determinants of human dipeptidyl peptidase III sensitivity to thiol modifying reagents
}

\begin{abstract}
Human dipeptidyl peptidase III (DPP III) is a member of the metallopeptidase family M49, involved in protein metabolism and oxidative stress response. DPP III crystal structure shows the two lobe-like domains separated by a wide cleft. The human enzyme has a total of six cysteines, three in the lower (Cys19, Cys147, and Cys176) and three in the upper (Cys509, Cys519, and Cys654), catalytic, domain containing the activesite zinc ion. To elucidate the molecular basis of this enzyme's susceptibility to sulfhydryl reagents, biochemical analysis of a set of Cys to Ala mutants was used, supported by mass spectrometry. Cys176, a residue $44 \AA$ apart from the catalytic center of the ligand-free enzyme, was found responsible for the inactivation with the submicromolar concentration of an organomercurial compound, and three additional cysteines contributed to sensitivity to aromatic disulfides. Upon treatment with oxidized glutathione [glutathione disulfide (GSSG)], cysteine residues at positions 147, 176, and 654 were found glutathionylated. The mutational analysis confirmed the involvement of Cys176 and Cys654 in human DPP III inactivation by GSSG. Observation that Cys176, a residue quite distant from the active center, contributes to enzyme inactivation, indicates that the substrate-binding site of human DPP III comprises both lower and upper protein domain.
\end{abstract}

Keywords: glutathionylation; mass spectrometry; metallopeptidase M49; reactive cysteines; sulfhydryl reagent.

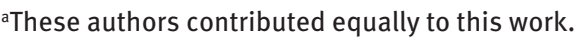

*Corresponding author: Marija Abramić, Division of Organic Chemistry and Biochemistry, Ruder Bošković Institute, Bijenička cesta 54, 10002 Zagreb, Croatia, e-mail: abramic@irb.hr Zrinka Karačić: Department of Chemistry, Faculty of Science, University of Zagreb, Horvatovac 102a, Zagreb, Croatia Jasminka Špoljarić: Division of Organic Chemistry and Biochemistry, Ruđer Bošković Institute, Bijenička cesta 54, 10002 Zagreb, Croatia

Marko Rožman: Division of Physical Chemistry, Ruđer Bošković Institute, Bijenička cesta 54, 10002 Zagreb, Croatia

\section{Introduction}

Dipeptidyl peptidase III (DPP III, EC 3.4.14.4) is a monozinc metalloexopeptidase, which in vitro hydrolyzes a number of biologically active peptides by cleaving dipeptides from their N-termini (Abramić et al., 1988; Chen and Barrett, 2004). This type of enzyme is broadly distributed in mammalian tissues and biochemically characterized from several eukaryotic sources (Fukasawa et al., 1998; Chen and Barrett, 2004; Jajčanin-Jozić et al., 2010). Based on the large proteomics datasets measured from seven human cell lines, DPP III is identified as a member of the human central proteome (Burkard et al., 2011). It is thought that this peptidase participates in normal intracellular protein catabolism, in the pain modulation, and in endogenous defense against oxidative stress (Chiba et al., 2003; Baršun et al., 2007; Liu et al., 2007). A pathological role is indicated for DPP III in cataractogenesis and in malignant growth (Zhang et al., 2001; Šimaga et al., 2003). Most recent clinical cancer research revealed the diagnostic and prognostic value of human DPP III as a constituent of the six-gene model (He et al., 2010).

Human DPP III belongs to the M49 family of metallopeptidases (DPP III family) (MEROPS database: http:// merops.sanger.ac.uk/) with five evolutionary conserved amino acid sequence regions (Abramić et al., 2004a). Crystal structures of two members of this family have been solved, yeast and human ortholog, both ligand-free (PDB: $3 c s k$ and $3 f v y$, respectively). These structures reveal that DPP III is a two-domain protein: upper domain (C-terminal) with the catalytic zinc ion bound, is mostly helical, separated by a wide cleft from the lower domain ( $\mathrm{N}$-terminal), comprising mixed $\alpha$ - and $\beta$-secondary structures (Baral et al., 2008). The zinc-binding site of the human DPP III is built up by His450, His455, and Glu508. The two histidine ligands belong to the conserved HEXXGH motif, characteristic of the M49 family, which is part of an $\alpha$-helix. The third ligand, Glu508, is a constituent of the second conserved hexapeptide, E-E-(CAT)-(RK)-A-(ED), situated on the neighboring $\alpha$-helix. In all eukaryotic sequences of M49 peptidases, this linear motif is the hexapeptide 
EECRAE (Abramić et al., 2004a). Two other glutamic acid residues in EECRAE motif (Glu507 and Glu512 in human DPP III) are hydrogen bonded to the zinc-coordinating histidine residues (His455 and His450).

Inhibition by thiol selective reagents is a general feature of all hitherto experimentally characterized M49 peptidases, indicating the presence of a reactive cysteine residue in (or close to) the active site (Abramić et al., 2004b; Jajčanin-Jozić et al., 2010). As all known DPPs III are multicysteine proteins, and there is no $100 \%$ conserved Cys within the M49 family, the identity of reactive -SH groups important for activity seems to be species specific. Recently, we reported that modification of Cys639 and Cys518 leads to catalytic inactivation of the yeast DPP III (Jajčanin-Jozić et al., 2010). Human DPP III has a total of six cysteines, three in the lower (Cys19, Cys147, and Cys176) and three in the upper domain (Cys509, Cys519, and Cys654) (Figure 1). Our previous study on an enzyme purified from human erythrocytes has revealed its inhibition by several sulfhydryl-modifying reagents, including the oxidized glutathione, and especially high sensitivity toward organomercurial compounds (Abramić et al., 2000, 2004b). To elucidate the molecular determinants of human DPP III inactivation by thiol reagents, we prepared six mutated enzyme forms with single cysteine to alanine substitutions and examined their properties. In addition, we employed the mass spectrometry (MS) approach to identify the target sites for oxidized glutathione on human DPP III.

\section{Results}

\section{Expression, purification, and biochemical characterization of wild-type and mutant DPP III proteins}

Each of the cysteine residues (positions 19, 147, 176, 509, 519, and 654 in the amino acid sequence) in human DPP III molecule was substituted by alanine independently. The wild-type and DPP III mutants were purified as His-tagged proteins of molecular mass $\sim 82 \mathrm{kDa}$. Figure 2 shows the purification profile for the wild-type DPP III.

The catalytic properties of the wild-type and all mutated forms were determined for the hydrolysis of characteristic synthetic substrate Arg-Arg-2-naphthylamide ( $\left.\operatorname{Arg}_{2}-2 \mathrm{NA}\right)$ (Table 1). The single mutants C19A, C147A, C509A, C519A, and C654A exhibited comparable kinetic parameters to the wild-type enzyme. However, replacement of Cys176 with Ala increased the $K_{\mathrm{M}}$ value

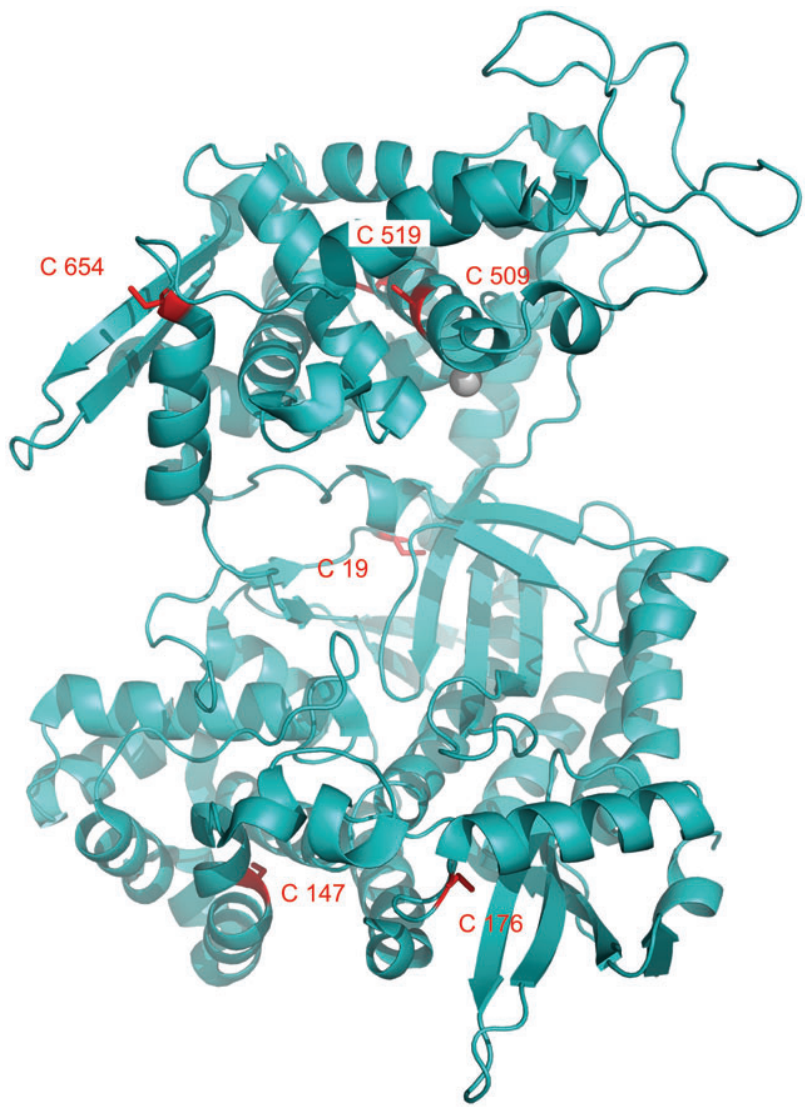

Figure 1 Overview of the human DPP III crystal structure (Protein Data Bank code: 3fvy).

Cysteine residues are presented as red sticks, and the catalytic zinc ion is shown as a gray sphere. The drawing was performed by PyMOL (www.pymol.org).

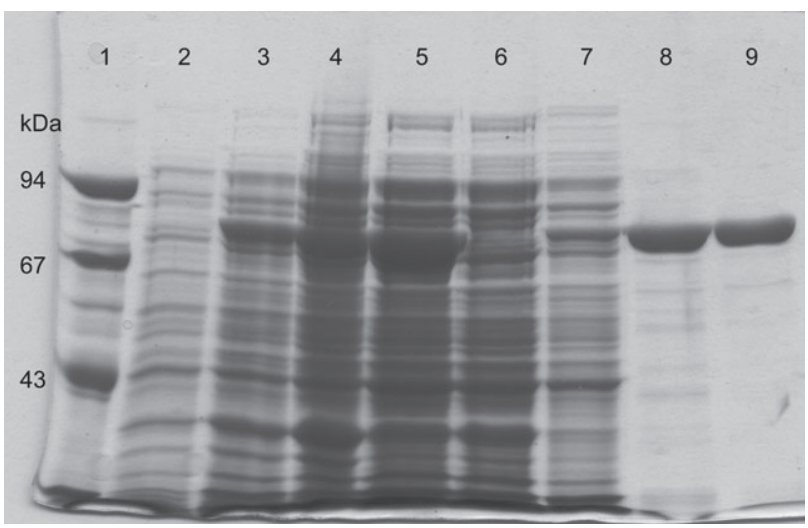

Figure 2 SDS-PAGE profile of total cell lysate and the purification progress of human DPP III-His ${ }_{6}$ protein on Ni-NTA agarose column. Lanes: 1, molecular mass marker; 2, total Escherichia coli cell lysate of uninduced sample; 3 , total cell lysate of induced sample; 4 , solubilized precipitate after cell lysate centrifugation; 5 , cleared cell lysate (supernatant after centrifugation); 6, flow-through Ni-NTA column; 7, wash with $20 \mathrm{~mm}$ imidazole; 8-9, human DPP III-His protein eluted with $150 \mathrm{~mm}$ imidazole. Proteins were stained with Coomassie Blue. 


\begin{tabular}{lrrr} 
DPP III form & $\boldsymbol{\kappa}_{M}(\boldsymbol{\mu})$ & $\boldsymbol{k}_{\text {cat }}(/ \mathbf{s})$ & $\begin{array}{r}\boldsymbol{k}_{\text {cat }} / \boldsymbol{K}_{M} \\
(/ \mu \mathrm{M} \mathrm{s})\end{array}$ \\
\hline Wild-type & $10.2 \pm 0.6$ & $50.8 \pm 9.2$ & $5.0 \pm 1.2$ \\
C19A & $5.8 \pm 0.2$ & $52.0 \pm 0.5$ & $8.9 \pm 0.2$ \\
C147A & $6.6 \pm 0.4$ & $58.6 \pm 1.2$ & $8.9 \pm 0.7$ \\
C176A & $35.3 \pm 9.4$ & $13.5 \pm 1.6$ & $0.39 \pm 0.06$ \\
C509A & $7.6 \pm 1.8$ & $34.4 \pm 2.7$ & $4.6 \pm 0.7$ \\
C519A & $12.2 \pm 1.0$ & $29.7 \pm 9.9$ & $2.4 \pm 0.6$ \\
C654A & $7.5 \pm 1.8$ & $55.7 \pm 7.6$ & $7.6 \pm 0.8$ \\
\hline
\end{tabular}

Table 1 Kinetic characterization of DPP III mutant proteins. The kinetic parameters were determined from the initial reaction rates at $25^{\circ} \mathrm{C}$ and at $\mathrm{pH} 8.6$ in the presence of $50 \mu \mathrm{M} \mathrm{CoCl}$, with the substrate ( $\left.\operatorname{Arg}_{2}-2 \mathrm{NA}\right)$ ranging from 2.5 to $60 \mu \mathrm{M}$, using a Hanes plot. Mean values $\pm S D$ are given.

for $\mathrm{Arg}_{2}$-2NA threefold, and decreased the $k_{\text {cat }}$ about fourfold, thus lowering the catalytic efficiency by an order of magnitude.

We further investigated if decreased hydrolytic activity of C176A reflects the change in protein structure. Circular dichroism (CD) spectroscopy in the far ultraviolet spectral region (Supplementary Figure 1) revealed almost identical CD spectra for the wild-type and C176A mutant, suggesting that Cys176-to-Ala substitution did not change human DPP III secondary structure. In addition, CD spectroscopy was used to monitor thermal denaturation of the C176A protein variant and the wild-type. A two-step unfolding was indicated for both, and the $\mathrm{T}_{\mathrm{m}}$ values did not differ significantly $\left(51.0 \pm 0.4^{\circ} \mathrm{C}\right.$ and $70.5 \pm 0.2^{\circ} \mathrm{C}$ for the $\mathrm{C} 176 \mathrm{~A} ; 49.9 \pm 0.3^{\circ} \mathrm{C}$ and $69.1 \pm 0.2^{\circ} \mathrm{C}$ for the wild-type). Identical thermal stability suggested that the Cys176-to-Ala substitution did not affect overall stability of human DPP III.

\section{Effects of cysteine substitution on the response to thiol-sensitive reagents}

We investigated the effect of four $\mathrm{SH}$ group-modifying reagents on the activity of wild-type human DPP III and its cysteinyl mutants: para-hydroxymercuribenzoate (pHMB), N-ethylmaleimide (NEM), 4,4'-dithiodipyridine (DTDP), and 5,5'-dithiobis(2-nitrobenzoic acid) (DTNB).

As shown in Figure 3A, as low as $0.01 \mu \mathrm{m}$ pHMB caused $50 \%$ loss of catalytic activity of the wild-type and all mutants, except the C176A. When the reagent concentration reached $0.1 \mu \mathrm{M}$, inactivation was almost $100 \%$ in the C19A, C147A, C654A, and the wild-type, 90\% in the C509A and C519A, while the C176A was resistant, exerting only $15 \%$ lower activity. This enzyme variant was found resistant to up to $1 \mu \mathrm{m}$ pHMB (data not shown), which is
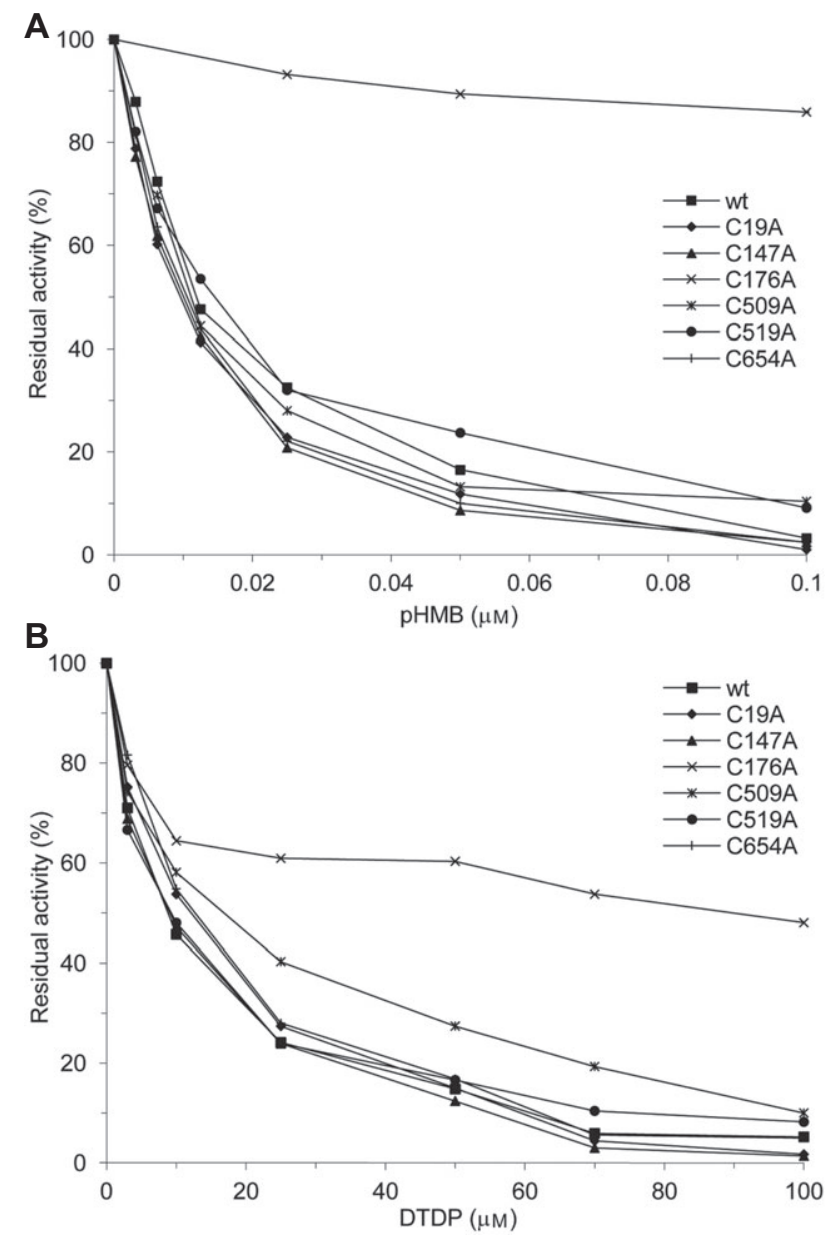

Figure 3 Inactivation of the wild-type human DPP III and of Cys-toAla mutants by pHMB (A) and by DTDP (B).

The purified enzyme $\left(2 \times 10^{-10} \mathrm{M}\right.$ wild-type or any of Cys-to-Ala mutants, except the $\left(176 \mathrm{~A}\right.$, which was $3 \times 10^{-9} \mathrm{M}$ ) was preincubated with pHMB or DTDP in $50 \mathrm{~mm}$ Tris- $\mathrm{HCl}$ buffer, $\mathrm{pH} 8.6$ at $25^{\circ} \mathrm{C}$ for $10 \mathrm{~min}$. Then, the residual activity was determined by a standard assay at $37^{\circ} \mathrm{C}$ with $\mathrm{Arg}_{2}-2 \mathrm{NA}$ as a substrate. Presented are averages of at least two determinations.

almost 2 orders of magnitude higher than the concentration that caused inactivation of other mutated forms.

All human DPP III variants were resistant to sulfhydryl-alkylating agent NEM, which only in $20 \mathrm{~mm}$ concentration decreased the wild-type activity by $30 \%$ (data not shown).

The aromatic disulfide DTDP is an amphiphilic uncharged reagent known to access the thiols located in a hydrophobic environment (Hansen and Winther, 2009).

DTDP, in a concentration range of 3-100 $\mu \mathrm{M}$, inactivated the wild-type and C19A, C147A, C519A, and C654A to the similar extent (Figure 3B). However, the enzyme variants lacking Cys176 or Cys509 showed high, respectively, moderate resistance. 
Enzyme form

\begin{tabular}{lrr}
\cline { 2 - 3 } & $\mathbf{0 . 5} \mathbf{~}$ in & 30 $\mathbf{~ m i n}$ \\
\hline Wild-type & $27.8 \pm 2.9$ & $24.8 \pm 2.0$ \\
C19A & $37.9 \pm 2.3$ & $32.5 \pm 0.9$ \\
C147A & $36.1 \pm 4.5$ & $32.3 \pm 4.7$ \\
C176A & $44.8 \pm 5.6$ & $45.1 \pm 2.8$ \\
C509A & $29.7 \pm 0.0$ & $24.3 \pm 0.3$ \\
C519A & $19.4 \pm 0.1$ & $15.1 \pm 1.9$ \\
C654A & $34.9 \pm 0.8$ & $29.9 \pm 1.4$ \\
\hline
\end{tabular}

Table 2 Influence of DTNB on the activity of human DPP III. The enzyme $\left(1.4 \times 10^{-7} \mathrm{M}\right)$ was incubated with $5 \mathrm{~mm}$ DTNB in $0.25 \mathrm{M}$ Tris- $\mathrm{HCl}$ buffer, $\mathrm{pH} 7.4$ at $25^{\circ} \mathrm{C}$ for 0.5 or $30 \mathrm{~min}$. Aliquots ( 3 to $7 \mu \mathrm{l}$ ) were taken at the indicated times and residual activity determined by standard assay. Mean values \pm SD are given.

DTNB (5 mM) caused rapid inactivation of human DPP III at $\mathrm{pH} 7.4$ and $23^{\circ} \mathrm{C}$ : after only $30 \mathrm{~s}$ preincubation, the loss of enzyme activity was $55 \%$ (the $\mathrm{C} 176 \mathrm{~A}$ variant) to $75 \%$ (the wild-type) (Table 2). Further incubation up to 30 min did not increase the inactivation extent significantly (Table 2). The C509A variant behaved as the wild-type. C19A and C654A seemed to be less inactivated than the wild-type, and the absence of Cys519 increased the inactivation rate (Table 2 ).

Results indicate, beside Cys176, two other residues reactive with DTNB - Cys19 and Cys654. The modification of Cys176 seems to contribute to the observed enzyme inactivation slightly more than those of Cys19 and Cys654.

\section{Influence of oxidized glutathione (glutathione disulfide, GSSG) on DPP III activity}

At first, concentration dependence of GSSG on the wildtype DPP III activity was investigated. After a 30-min incubation at $25^{\circ} \mathrm{C}$ at physiological pH, GSSG, in concentrations above $2 \mathrm{~mm}$, decreased the enzyme's activity to about $20 \%$ of the original value (data not shown).

To find out if any single cysteine residue is responsible for the observed inactivation of human DPP III by GSSG, all prepared enzyme forms were incubated with $3 \mathrm{~mm}$ GSSG at pH 7.4. Under these conditions, the wildtype and two mutants, C19A and C147A, lost about 90\% of activity, while C176A and C519A retained significantly more activity than the wild-type (Table 3).

Obtained results showed that the inactivation effect of GSSG cannot be ascribed to the modification of only one cysteine residue (Table 3).

\begin{tabular}{lrr} 
& \multicolumn{2}{c}{ Residual activity (\%) } \\
\cline { 2 - 3 } & $\mathbf{1 5} \mathrm{min}$ & $\mathbf{3 0 ~ \mathrm { min }}$ \\
\hline Wild-type & $11.6 \pm 4.4$ & $8.5 \pm 2.6$ \\
C19A & $11.4 \pm 1.0$ & $8.1 \pm 2.9$ \\
C147A & $10.7 \pm 0.0$ & $8.1 \pm 3.4$ \\
C176A & $38.6 \pm 4.3$ & $25.6 \pm 3.6$ \\
C509A & $17.1 \pm 2.8$ & $12.5 \pm 2.1$ \\
C519A & $30.9 \pm 2.8$ & $23.6 \pm 2.7$ \\
C654A & $15.7 \pm 0.8$ & $13.2 \pm 0.4$ \\
\hline
\end{tabular}

Table 3 Influence of oxidized glutathione on the activity of wild-type and cysteinyl mutants of human DPP III.

The enzyme $\left(1.3 \times 10^{-7} \mathrm{M}\right)$ was incubated for 15 or 30 min with $3 \mathrm{~mm}$ GSSG at $25^{\circ} \mathrm{C}$ and pH 7.4 ( $25 \mathrm{~mm}$ Tris- $\mathrm{HCl}$ buffer). Aliquots ( 2 to 25 $\mu \mathrm{l})$ were taken at the indicated times and the residual activity determined by standard activity assay. Mean values \pm SD are given.

\section{Identification of glutathionylation sites of human DPP III}

To identify human DPP III Cys residues which are the glutathionylation sites, mass spectrometric analysis of GSSGmodified enzyme was performed as described in the Materials and methods.

The wild-type enzyme was reacted with $3 \mathrm{~mm}$ GSSG for $30 \mathrm{~min}$ at room temperature. Subsequently, GSSGtreated DPP III was alkylated with 2-iodoacetamide (IAM), and the protease digestion was performed. Resulting peptide mixture was analyzed by on-line reverse-phase LC tandem MS (as described in the Materials and methods section). Obtained tandem MS spectra were matched against protein sequence of human DPP III (UniProtKB entry: Q9NY33). Additional crosscheck against common contaminants database returned no significant matches.

Tryptic digestion yielded a sequence coverage of $74 \%$, and five peptides containing cysteine residues (Cys 19, Cys 147, Cys 176, Cys 509, Cys 654) were identified (Table 4). Despite our efforts (different digestion conditions and optimizing digestion protocol), the peptide containing Cys 519 residue was not observed, most likely due to the fact that it is relatively large (38 amino acids) and hydrophobic. In order to produce smaller proteolytic fragments, a chymotryptic digestion was performed. The chymotryptic map resulted in a coverage of $76 \%$ and revealed a peptide containing Cys 519.

Tandem MS data of both (tryptic and chymotryptic) peptide maps yielded comparative results. Taken all together, tandem MS characterization showed glutathionylation as well as carboxyamidomethylation on Cys residues 147, 176, and 654 (Table 4). By contrast, peptides 


\begin{tabular}{|c|c|c|c|c|c|}
\hline Fragment & $\begin{array}{r}\text { Cys } \\
\text { residue }\end{array}$ & Amino acid sequence & {$[\mathrm{M}+\mathrm{H}]_{\mathrm{m}}^{+}$} & {$[M+H]^{+}{ }_{c}$} & $\Delta$ \\
\hline $1-20$ & 19 & MADTQYILPNDIGVSSLDCֵR & 2426.28 & 2426.133 & 0.147 \\
\hline $142-157$ & 147 & GLWQTCGGELMFSLEPR & 1924.068 & 1923.909 & 0.159 \\
\hline $145-152$ & 147 & $\mathrm{QTC} * \mathrm{GELMF}$ & 1233.472 & 1233.458 & 0.014 \\
\hline $166-182$ & 176 & EGTTTYFSGNCTMEDAK & 1911.858 & 1911.774 & 0.084 \\
\hline $166-182$ & 176 & EGTTTYFSGNC*TMEDAK & 2159.838 & 2159.82 & 0.018 \\
\hline $499-510$ & 509 & FSTIASSYEECR & 1449.652 & 1449.631 & 0.021 \\
\hline $518-528$ & 519 & LCLLHPQVLEIF & 1368.724 & 1368.734 & 0.01 \\
\hline $639-659$ & 654 & ALYEGYATVTDAPPECFLTLR & 2387.1 & 2387.159 & 0.059 \\
\hline $639-659$ & 654 & ALYEGYATVTDAPPEC ${ }^{\star} F L T L R$ & 2635.29 & 2635.205 & 0.085 \\
\hline
\end{tabular}

Table 4 Characterized Cys-containing peptides resulting from the human DPP III protease digests. c, calculated; ${ }_{m}$, measured and deconvoluted. Glutathionylated Cys are shown in bold, with asterisk, while carboxyamidomethylated Cys are underlined. Accompanying tandem MS spectra are given as supporting data (Supplementary Figures 2-10 and corresponding Supplementry Tables 2-10). The wild-type human DPP III was glutathionylated, digested by trypsin or chymotrypsin, and analyzed by LC-MS/MS as described in the Materials and methods section.

containing Cys 19, Cys 509, and Cys 519 were found only to be carboxyamidomethylated.

Combined results of mutational analysis and MS suggest that glutathionylation (formation of mixed disulfide) of Cys176 and Cys654 contributes to human DPP III inactivation by oxidized glutathione.

\section{Discussion}

Finding that only the C176A protein retained substantial enzymatic activity upon treatment with submicromolar pHMB is consistent with this residue being essential for the inactivation of human DPP III mediated by this organomercurial compound. Li et al. (2000) investigated the properties of the recombinant rat DPP III using sitedirected mutagenesis approach and found that only Cys176-to-Ala mutant is resistant to both $p$-chloromercuribenzoic acid (PCMB, in submicromolar concentration range) and NEM (up to $2 \mathrm{mM}$ ). Human DPP III is highly homologous (93.5\% identity of the amino acid sequence) to its rat counterpart. The results of our present study demonstrate significant differences in sensitivity of the wild-type human enzyme toward the organomercurial compound (it is much higher), and toward NEM (it is much lower), compared to the rat DPP III. Li et al. concluded that out of a total of seven cysteine residues in the rat DPP III (positions 19, 147, 176, 509, 519, 654, and 701), Cys176 is essential for the regulation of rat DPP III activity. However, our present findings of the influence of five different $\mathrm{SH}$ group modifiers on the human DPP III demonstrate that a variety of sulfhydryl reagents are able to inactivate human
DPP III, but except for the organomercurial compound pHMB, inactivation cannot be explained by the modification of only one cysteine residue.

The $K_{\mathrm{M}}$ value of the rat C176A mutant was unchanged, and the $k_{\text {cat }}\left(\right.$ and $\left.k_{\text {cat }} / K_{\mathrm{M}}\right)$ was lowered about twofold compared to the wild-type ( $\mathrm{Li}$ et al., 2000). In contrast, the human variant lacking Cys176 was found to be significantly less active (12-fold decrease in $k_{\text {cat }} / K_{\mathrm{M}}$ value). Observed change in $K_{\mathrm{M}}$ value indicates that Cys176 may contribute to the substrate binding of human DPP III. This is supported by our previous finding that the peptide substrate protects the human DPP III from inactivation by pHMB (Abramić et al., 2004b). The difference in thiol sensitivity and catalytic properties of C176A mutants of the recombinant rat and human enzyme is not surprising, as earlier comparative investigation of native enzymes (purified from human and rat erythrocytes) indicated non-identity in their active site topology (Abramić et al., 2000). So far, no 3-D structure of the rat enzyme is available, and detailed structural comparison is not possible.

Our results point to the Cys176 as the residue reactive with various SH reagents (pHMB, DTDP, DTNB) and GSSG. However, modification of Cys176 is critical for the inactivation of human DPP III only with the organomercurial compound. In addition to Cys176, at least three other cysteine residues (Cys147, Cys509, and Cys654) are able to react with different thiol-selective compounds, including the biologically active GSSG, and may contribute to (reversible) inactivation of the enzyme.

The reactivity of protein cysteinyl thiols is regulated by a number of factors: exposure to a solvent, dissociation to the thiolate anion, reactivity of the $\mathrm{SH}$ reagent, nature of the leaving group of the reagent, charge compatibility 
between the reagent and cysteine environment, and stability of the bonds formed (Britto et al., 2002). Considering the local surrounding, ionization of the $\mathrm{SH}$ groups is enhanced by the neighboring basic amino acids and suppressed by acidic groups. To explain the observed differences in the reactivity of human DPP III cysteinyl residues, we analyzed their location and microenvironment in the protein crystal structure (Supplementary Table 1). Only Cys654 was found to be highly surface exposed, while Cys19, Cys147, and Cys176 are located near the external surface, but are not directly exposed to the solvent. The surface- or near-surface location correlates well with the reactivity toward GSSG for all residues (Cys654, Cys147, and Cys176) except the Cys19 whose modification was not detected by MS. The lack of reactivity of Cys19 could be explained by the absence of any neighboring positively charged group, and the presence of Asp377 in the proximity (5.2 $\AA$ apart) of the sulfur, which may suppress the formation of thiolate anion, but also produce the charge repulsion due to the incompatibility with the negatively charged reagent (GSSG).

Our results indicate Cys176 as probably the most reactive cysteine residue in human DPP III. Inspection of the location and environment of this residue in the X-ray crystal structure supports this conclusion (Table 5). The $\varepsilon$-amino group of Lys202, $5.3 \AA$ apart, faces the sulfur of Cys176 and could promote ionization of the thiol group. Arg325 is the other basic residue near Cys176 (Table 5), but the distance to its guanidino group is $8.1 \AA$. There is also one acidic residue on the 4.4-A distance (Asp180). However, additional influence on the lowering of the $\mathrm{pKa}$ of Cys176 could be exerted through a potential hydrogen bond between its SH group and the Ser173 which are only $3.5 \AA ̊$ apart (Table 5).

In addition to Cys176, whose reactivity is governed by its microenvironment and near-surface location, the hydrophobic pocket-buried Cys509 from the conserved EECRAE motif seemed to contribute to human DPP III inactivation

\begin{tabular}{llr} 
Residue & Atom & $\begin{array}{r}\text { Distance } \\
(\AA)\end{array}$ \\
\hline Lys202 & Nitrogen of $\varepsilon$-amino & 5.26 \\
Arg325 & Nitrogen of guanidino & 8.14 \\
Asp180 & Oxygen of carboxylate & 4.36 \\
Ser173 & Hydroxyl oxygen & 3.54 \\
\hline
\end{tabular}

Table 5 Distances from Cys176 to neighboring residues. Distances were measured with PyMOL (www.pymol.org) from the sulfur of Cys176 to the listed atom, using the crystal structure of the human DPP III (code 3fvy in Protein Data Bank). by the aromatic disulfide DTDP (Figure 3B). Interestingly, the structurally equivalent Cys518 contributed significantly to the inactivation of the yeast DPP III with the same compound (Jajčanin-Jozić et al., 2010). These findings are in agreement with DTDP being an amphiphilic reagent able to access even buried sulfhydryl groups in proteins.

Prokaryotic M49 peptidases were discovered only recently, when their deduced amino acid sequences became available in public data bases (Abramić et al., 2004b). Majority of bacterial M49 peptidases comprise the conserved HECLGH motif. Unlike the eukaryotic members of the family, they contain a cysteine residue in close proximity to the catalytically essential Glu and to the two zinc-coordinating histidines. Most recently, we have reported that the Cys residue, from the active-site motif of the Bacteroides thetaiotaomicron DPP III, is wholly responsible for the inactivation by sulfhydryl reagents (Vukelić et al., 2012). The activity of yeast Saccharomyces cerevisiae DPP III was sensitive to the modification of two cysteine residues (Cys518 and Cys639). Based on those previous findings and our present study indicating at least three Cys in human DPP III whose chemical modification can influence the enzyme activity, it is clear that different mechanisms of the M49 peptidase thiol sensitivity are involved in different organisms. It seems that the number of "responsible" cysteines in DPP III family members increases with the complexity of the species (organism) from which they originate.

The results presented here provide experimental verification for prediction that highly reactive cysteine residue(s) is a part of the substrate-binding site of the mammalian DPPs III (Abramić et al., 2004b). Now, we have identified the highly reactive Cys176, which seems to contribute to the substrate binding to human DPP III. Surprisingly, this residue is located in the amino-terminal protein domain, which is considered to be noncatalytic. It is not clear how the Cys176, which is near the protein surface and at a 43.7-A distance from the zinc ion in the crystal structure of ligand-free human DPP III, could influence the substrate binding and how the modification of this residue by pHMB could cause complete inactivation of the enzyme. A possible explanation would be that human DPP III adapts also a more flexible conformation in solution, allowing the two domains ("upper" and "lower," "catalytic" and "noncatalytic") to operate in close proximity and thereby enabling Cys176 to participate in substrate binding. Whether the two conformations are present in equilibrium in solution, or the ligand binding triggers the conformational change (interdomain mobility), which is accompanying the catalytic cycle, is yet unknown and worthy of further investigations. 
It has been reported that human insulin-degrading enzyme (IDE), which belongs to the evolutionary distinct family of zinc metallopeptidases (M16), undergoes a switch between the closed and opened conformations for catalysis (Im et al., 2007). The conformational changes accompanying the catalytic cycle of the carbamoyl phosphate synthetase have also been documented (Hart and Powers-Lee, 2009).

Our present study shows that human DPP III can be glutathionylated under the oxidative stress conditions when mM concentrations of GSSG can be observed.

The data of the MS analysis suggest that the glutathionylation of the three cysteine residues (Cys176, Cys654, and Cys147) might be involved in the inactivation of human DPP III wild-type by oxidized glutathione. Interestingly, the residual activity assay pointed to Cys176 and Cys519. As the glutathionylation of Cys519 was not confirmed by MS, and the variant lacking Cys176 was highly sensitive to GSSG, modification of another cysteine(s) is involved in observed DPP III inactivation.

Glutathionylation of proteins is reversible, as those proteins can be reduced by glutaredoxins, and the process serves to regulate protein functions by the redox state of the cell (i.e., by the GSSG/GSH ratio) (Casagrande et al., 2002). Glutathionylation of human DPP III, as reversible modification, may provide protection against oxidative inactivation. In addition, as various biological events, including redox signaling, utilize proteins containing reactive sulfhydryls, DPP III cysteine residues may be important for (intracellular) protein interactions and yet with an unknown biological function different from proteolysis.

Although the potential role in protection against oxidative stress has been ascribed to human DPP III (Liu et al., 2007), a corresponding molecular mechanism remains unknown.

Taken together, the results of this investigation provide new information about the reactivity of individual cysteine residues within the human DPP III, which could be useful for further functional studies of the enzyme. The finding that Cys176, a residue from the lower domain, quite distant from the catalytic zinc ion, is responsible for the fast inactivation of the enzyme by the organomercurial compound and contributing to enzyme inactivation by DTDP, DTNB, and GSSG, provides the evidence that the active site (the substrate-binding site) of human DPP III comprises both protein domains, which in the active form of the enzyme need to be in close contact.

We conclude that Cys176 is not directly involved in catalysis, but that is, in the active (closed) form of the enzyme located in (or close to) the substrate-binding site and contributes to the ligand binding, so that the modification of this cysteine residue hinders the function of human DPP III.

\section{Materials and methods}

\section{Chemicals}

NEM, IAM, DTDP, pHMB, DTNB, formic acid, HPLC-grade water, and acetonitrile, as well as proteomics-grade trypsin were obtained from Sigma-Aldrich (St. Louis, MO, USA). Sequencing-grade chymotrypsin was purchased from Roche Applied Science (Mannheim, Germany) and nickel-nitrilotriacetic acid (Ni-NTA) agarose from Qiagen (Hilden, Germany). GSSG was a product of Serva (Heidelberg, Germany), and L-Arg-L-Arg-2-naphthylamide ( $\operatorname{Arg}_{2}$-2NA) trihydrochloride, from Bachem (Bubendorf, Switzerland).

\section{Cloning and site-directed mutagenesis}

To obtain the DPP III protein with affinity C-terminal six-histidine tag, full cDNA for DPP III (2.214 kb, contained originally in the clone IRALp962E0242Q2) (Salopek-Sondi et al., 2008) was cloned into pET21b vector between the NheI and XhoI restriction sites as described earlier (Špoljarić et al., 2011). Thus, the obtained wild-type expression vector was used for further mutagenesis and protein expressions.

\begin{tabular}{lll}
\cline { 2 - 3 } & Forward & Reverse \\
\hline pET21b-DPPIII6His C19A & GTG TCT AGC CTG GAC GCC CGT GAG GCC TTC C & G GAA GGC CTC ACG GGC GTC CAG GCT AGA CAC \\
pET21b-DPPIII6His C147A & GGC CTC TGG CAG ACC $\underline{\text { GCC GGG GAG CTT ATG }}$ & CAT AAG CTC CCC GGC GGT CTG CCA GAG GCC \\
pET21b-DPPIII6His C176A & CC TAT TTC TCT GGG AAT GCT ACC ATG GAA GAT GCC & GGC ATC TTC CAT GGT AGC ATT CCC AGA GAA ATA GG \\
pET21b-DPPIII6His C509A & CC AGC TAC GAA GAG GCC CGG GCT GAG AGC GTG GG & CC CAC GCT CTC AGC CCG GGC CTC TTC GTA GCT GG \\
pET21b-DPPIII6His C519A & GTG GGT CTC TAC CTC $\underline{\text { GCT CTC CAC CCG CAA GTG }}$ & CAC TTG CGG GTG GAG AGC GAG GTA GAG ACC CAC \\
pET21b-DPPIII6His C654A & GAT GCG CCC CCC GAG GCC TTC CTC ACC CTC AGG & CCT GAG GGT GAG GAA GGC CTC GGG GGG CGC ATC \\
\hline
\end{tabular}

Table 6 Oligonucleotides used for PCR-based site-directed mutagenesis.

The codons changed are underlined and appear in bold. 
The production of cysteine-to-alanine point mutations was performed by means of the QuikChange II XL Site-Directed Mutagenesis kit (Stratagene, La Jolla, CA, USA) and the primers listed in Table 6. The sequencing of the complete DPP III gene, as well as confirmation of each mutant, was obtained with automated sequence analyzer "ABI PRISM ${ }^{\circledast}$ 3100-Avant Genetic Analyzer" (Applied Biosystems, Concord, MA, USA).

\section{Expression and purification of the enzymes}

Heterologous expression of recombinant DPP III with C-terminal sixhistidine tag, and purification on Ni-NTA agarose was performed as described by Špoljarić et al. (2011).

Protein purity was confirmed by polyacrylamide gel electrophoresis (PAGE) under native and denaturing conditions (SDS-PAGE) carried out according to the method of Laemmli (1970). All fractions of high purity (according to the SDS-PAGE analysis) were pooled and desalted on PD-10 columns (Amersham Biosciences, Vienna, Austria) equilibrated with $20 \mathrm{~mm}$ Tris-HCl buffer ( $\mathrm{pH}$ 7.4) containing $1 \mathrm{~mm} \mathrm{NaCl}$. To the purified protein preparations, glycerol was added to $22 \%$, and they were stored at $-10^{\circ} \mathrm{C}$.

Protein concentrations were determined using the protein-dye binding assay, with bovine serum albumin as a standard (Bradford, 1976).

\section{Enzyme activity assay and determination of kinetic parameters}

The enzymatic activities of the wild-type DPP III and enzyme variants were determined by a standard assay at $37^{\circ} \mathrm{C}$ with $\mathrm{Arg}_{2}-2 \mathrm{NA}$ as a substrate (Abramić et al., 2004b). Kinetic parameters were determined at $25^{\circ} \mathrm{C}$ and at $\mathrm{pH} 8.6$, in the presence of $50 \mu \mathrm{M} \mathrm{CoCl}_{2}$ by initial rate measurements (Špoljarić et al., 2009).

\section{Circular dichroism (CD) measurements}

CD spectra were recorded on Jasco J-815 spectropolarimetar with automatic temperature control using a quartz cuvette of $0.1 \mathrm{~mm}$ path length. Enzyme samples were prepared for $\mathrm{CD}$ measurements by exchange into $10 \mathrm{~mm}$ Tris- $\mathrm{HCl}$ buffer, $\mathrm{pH}$ 7.4. The protein concentrations used were from 0.31 to $0.39 \mathrm{mg} / \mathrm{ml}$. Recording of the farUV spectra, acquisition of thermal denaturation data, and analysis of protein secondary structure from CD spectra were performed as described (Jajčanin-Jozić et al., 2010).

\section{Inactivation by sulfhydryl reagents and glutathione disulfide}

The purified enzyme $\left(2 \times 10^{-10} \mathrm{M}\right.$ wild-type or any of the Cys-to-Ala mutants, except the $\mathrm{C} 176 \mathrm{~A}$, which was $3 \times 10^{-9} \mathrm{M}$ ) was preincubated with pHMB (0.003 to $0.1 \mu \mathrm{M}$ ) or DTDP (3 to $100 \mu \mathrm{M}$ ) in $50 \mathrm{~mm}$ Tris-HCl buffer, $\mathrm{pH} 8.6$ at $25^{\circ} \mathrm{C}$ for $10 \mathrm{~min}$. Then, the substrate $\operatorname{Arg}_{2}-2 \mathrm{NA}$ was added and residual activity determined under the standard assay conditions.

NEM, in a concentration range of $1-20 \mathrm{mM}$, was preincubated with an enzyme $\left(2.0 \times 10^{-7} \mathrm{M}\right)$ in $100 \mathrm{~mm}$ sodium phosphate buffer, $\mathrm{pH}$ 7.0 at $25^{\circ} \mathrm{C}$. Ten $\mu$ l aliquots were taken after $10 \mathrm{~min}$ for the determination of residual activity at $\mathrm{pH}$ 8.6.

DTNB, $5 \mathrm{~mm}$, and $1.4 \times 10^{-7} \mathrm{M}$ enzyme were preincubated in $0.25 \mathrm{M}$ Tris- $\mathrm{HCl}$ buffer, $\mathrm{pH} 7.4$ at $25^{\circ} \mathrm{C}$ for $0.5 \mathrm{~min}$ or $30 \mathrm{~min}$. Threeto seven-microliter aliquots were taken for the remaining activity determination.

When modification with oxidized glutathione (GSSG) was investigated, typically, the enzyme $\left(1.3 \times 10^{-7} \mathrm{M}\right)$ was incubated for 15 or 30 min at $25^{\circ} \mathrm{C}$ in a total volume of $150 \mu \mathrm{l}$ of reaction mixture $\mathrm{pH} 7.4$ (25 $\mathrm{mm}$ Tris-HCl buffer) with $3 \mathrm{~mm} \mathrm{GSSG}$, added from a stock solution of $50 \mathrm{~mm}$ GSSG dissolved in $25 \mathrm{~mm}$ Tris- $\mathrm{HCl}$ buffer, $\mathrm{pH}$ 7.4. Residual DPP III activity was determined at the end of incubation, with 2 to $25 \mu \mathrm{l}$ aliquots taken for a standard activity assay.

For MS analysis, the reaction with GSSG (glutathionylation) was terminated by the addition of IAM to $0.05 \mathrm{M}$, followed by $20 \mathrm{~min}$ incubation at $25^{\circ} \mathrm{C}$, and $5 \mathrm{~min}$ incubation at $95^{\circ} \mathrm{C}$. After $40 \mathrm{~min}$ at $25^{\circ} \mathrm{C}$, the sample was digested by trypsin, during a 1-h incubation at $37^{\circ} \mathrm{C}$ in $80 \%$ acetonitrile, $20 \% 50 \mathrm{~mm}$ Tris- $\mathrm{HCl}, 10 \mathrm{~mm} \mathrm{CaCl}_{2} \mathrm{pH}$ $7.6(\mathrm{v} / \mathrm{v})$ (Strader et al., 2006), with 1:20 w/w ratio of trypsin and DPP III, or chymotrypsin (incubation for $2 \mathrm{~h}$ at $25^{\circ} \mathrm{C}$ in $15 \mathrm{~mm}$ Tris- $\mathrm{HCl}$ pH 8.6 with $10 \mathrm{mM} \mathrm{CaCl}_{2}, 1: 20 \mathrm{w} / \mathrm{w}$ ratio of chymotrypsin and DPP III, as suggested in the Roche Protocols).

\section{Liquid chromatography (LC) separation and tandem mass spectrometry (MS/MS)}

Online LC-MS/MS analysis was performed on a Bruker amaZon ETD ion trap system (Bruker Daltonik GmbH, Bremen, Germany) coupled with an Ultimate 3000 RSLCnano system (Dionex, Amsterdam, Netherlands). The sample injection, enrichment, separation, and MS acquisition was carried out automatically. The peptide mixture was loaded ( $1 \mu \mathrm{l}$ injection volume) onto the trapping column (Nano Trap Column, $75 \mu \mathrm{m}$ I.D. $\times 2 \mathrm{~cm}$, Acclaim PepMap100 C18, $3 \mu \mathrm{m}$, $100 \AA$ A , Dionex, Amsterdam, Netherlands) with a solvent mixture of $0.1 \%$ formic acid in $\mathrm{CH}_{3} \mathrm{CN} / \mathrm{H}_{2} \mathrm{O}(2: 98, \mathrm{w} / \mathrm{w})$ at a flow rate of $20 \mu \mathrm{l} / \mathrm{min}$. For peptide separation Nano Trap Column, $75 \mu \mathrm{m}$ I.D. $\times 2 \mathrm{~cm}$, packed with Acclaim PepMap100 C18, 3 m , $100 \AA$ (Dionex) was used. Peptides were separated with a 80 min linear gradient from $2 \%$ to $40 \%$ acetonitrile in $0.1 \%$ formic acid at the flow rate of $300 \mathrm{nl} / \mathrm{min}$.

The nano-spray capillary voltage was set as $-1500 \mathrm{~V}$, while highvoltage end plate offset was $-500 \mathrm{~V}$. The temperature and flow rate of the drying gas were set at $140^{\circ} \mathrm{C}$ and $5 \mathrm{l} / \mathrm{min}$, respectively. Helium was used as the collision gas. The fragmentation amplitude was set at $1 \mathrm{~V}$ and ramped between $30 \%$ and $200 \%$ of this value. Product ion spectra were sequentially recorded for each selected precursor. The acquisition software was set up in autoMSMS mode using three to four precursor ions with active exclusion on (precursor exclusion after two MSMS spectrum for $0.3 \mathrm{~min}$ ). MS spectra were acquired within a scan range from 300 to $3000 \mathrm{~m} / \mathrm{z}$ and a scan speed of $8100(\mathrm{~m} / \mathrm{z}) / \mathrm{s}$ using averages from five spectra. MSMS spectra were acquired within a scan range from 100 to $2400 \mathrm{~m} / \mathrm{z}$ and a scan rate of $8100(\mathrm{~m} / \mathrm{z}) / \mathrm{s}$ using averages from 2 spectra.

DataAnalysis software 4.0 (Bruker Daltonik GmbH, Bremen, Germany) was used to extract MS and MS/MS data. Protein sequence assignment was attempted using BioTools 3.2 (Bruker Daltonik 
GmbH, Bremen, Germany). The maximum number of miscleavages for trypsin was set as one per peptide, while for chymotrypsin, it was set as up to six per peptide.

Acknowledgements: Support for this study by the Croatian Ministry of Science, Education and Sport (Projects
098-1191344-2938 and 098-0982915-2945) is gratefully acknowledged.

Received April 17, 2012; accepted July 2, 2012

\section{References}

Abramić, M., Zubanović, M, and Vitale, Lj. (1988). Dipeptidyl peptidase III from human erythrocytes. Biol. Chem. Hoppe-Seyler 369, 29-38.

Abramić, M., Schleuder, D., Dolovčak, Lj., Schröder, W., Strupat, K., Šagi, D., Peter-Katalinić, J., and Vitale, Lj. (2000). Human and rat dipeptidyl peptidase III: biochemical and mass spectrometric arguments for similarities and differences. Biol. Chem. 38, 1233-1243.

Abramić, M., Špoljarić, J., and Šimaga, Š., (2004a). Prokaryotic homologs help to define consensus sequences in peptidase family M49. Period Biol. 106, 161-168.

Abramić, M., Šimaga, Š., Osmak, M., Čičin-Šain, L., Vukelić, B., Vlahoviček, K., and Dolovčak, Lj. (2004b). Highly reactive cysteine residues are part of the substrate binding site of mammalian dipeptidyl peptidases III. Int. J. Biochem. Cell Biol. 36, 434-446.

Baral, P.K., Jajčanin-Jozić, N., Deller, S., Macheroux, P., Abramić, M., and Gruber, K. (2008). The first structure of dipeptidylpeptidase III provides insight into the catalytic mechanism and mode of substrate binding. J. Biol. Chem. 283, 2231622324.

Baršun, M., Jajčanin, N., Vukelić, B., Špoljarić, J., and Abramić, M (2007). Human dipeptidyl peptidase III acts as a postproline-cleaving enzyme on endomorphins. Biol. Chem. 388, 343-348.

Bradford, M.M. (1976). A rapid and sensitive method for the quantitation of microgram quantities of protein utilizing the principle of protein-dye binding. Anal. Biochem. 72, 248-254.

Britto, P.J., Knipling, L., and Wolff, J. (2002). The local electrostatic environment determines cysteine reactivity of tubulin. J. Biol. Chem. 277, 29018-29027.

Burkard, T.R., Planyavsky, M., Kaupe, I., Breitwieser, F., Bürckstümmer, T., Bennett, K.L., Superti-Furga, G., and Colinge, J. (2011). Initial characterization of the human central proteome. BMC Syst. Biol. 5, 17. doi: 10.1186/1752-0509-5-17.

Casagrande, S., Bonetto, V., Fratelli, M., Gianazza, E., Eberini, I., Massignan, T., Salmona, M., Chang, G., Holmgren, A., and Ghezzi, P. (2002). Glutathionylation of human thioredoxin: a possible crosstalk between the gluathione and thioredoxin systems. Proc. Natl. Acad. Sci. USA 99, 9745-9749.

Chen, J.-M. and Barrett, A.J. (2004). Dipeptidyl-peptidase III. In: Handbook of Proteolytic Enzymes, Vol. 1, A.J. Barrett, N.D. Rawlings, and J.F. Woessner, eds. (Amsterdam, The Netherlands: Elsevier Academic Press), pp. 809-812.

Chiba, T., Li, Y.-H., Yamane, T., Ogikubo, O., Fukuoka, M., Arai, R., Takahashi, S., Ohtsuka, T., Ohkubo, I., and Matsui, N. (2003). Inhibition of recombinant dipeptidyl peptidase III by synthetic hemorphin-like peptides. Peptides 24, 773-778.
Fukasawa, K., Fukasawa, K.M., Kanai, M., Fujii, S., Hirose, J., and Harada, M. (1998). Dipeptidyl peptidase III is a zinc metalloexopeptidase: molecular cloning and expression. Biochem. J. 329, 275-282.

Hansen, R.E. and Winther, J.R. (2009). An introduction to methods for analyzing thiols and disulfides: reactions, reagents, and practical considerations. Anal. Biochem. 394, 147-158.

Hart, E.J. and Powers-Lee, S.G. (2009). Role of Cys-1327 and Cys-1337 in redox sensitivity and allosteric monitoring in human carbamoyl phosphate synthetase. J. Biol. Chem. 284, 5977-5985.

He, M., Mangiameli, D.P., Kachala, S., Hunter, K., Gillespie, J., Bian, X., Shen, H.-C., and Libutti, S.K. (2010). Expression signature developed from a complex series of mouse models accurately predicts human breast cancer survival. Clin. Cancer Res. 16, 249-259.

Im, H., Manolopoulou, M., Malito, E., Shen, Y., Zhao, J., Neant-Fery, M., Sun, C.-Y., Meredith, S.C., Sisodia, S.S., Leissring, M.A., et al. (2007). Structure of substrate-free human insulindegrading enzyme (IDE) and biophysical analysis of ATP-induced conformational switch of IDE. J. Biol. Chem. 282, 25453-25463.

Jajčanin-Jozić, N., Deller, S., Pavkov, T., Macheroux, P., and Abramić, M. (2010). Identification of the reactive cysteine residues in yeast dipeptidyl peptidase III. Biochimie 92, 89-96.

Laemmli, U.K. (1970). Cleavage of structural proteins during the assembly of the head of bacteriophage T4. Nature 227, 680-685.

Li, Y.-H., Maeda, T., Yamane, T., and Ohkubo, I. (2000). Alteration of rat dipeptidyl peptidase III by site-directed mutagenesis: cysteine ${ }^{176}$ is a regulatory residue for the enzyme activity. Biochem. Biophys. Res. Commun. 276, 553-558.

Liu, Y., Kern, J., Walker, J.R., Johnson, J.A., Schultz, P.G., Luesch, H. (2007). A genomic screen for activators of the antioxidant response element. Proc. Natl. Acad. Sci. USA 104, 5205-5210.

Salopek-Sondi, B., Vukelić, B., Špoljarić, J., Šimaga, Š., Vujaklija, D., Makarević, J., Jajčanin, N., and Abramić, M. (2008). Functional tyrosine residue in the active center of human dipeptidyl peptidase III. Biol. Chem. 389, 163-167.

Strader, M.B., Tabb DL, Hervey, W.J., Pan C., and Hurst, G.B. (2006). Efficient and specific trypsin digestion of microgram to nanogram quantities of proteins in organic-aqueous solvent systems. Anal. Chem. 78, 125-134.

Šimaga, Š., Babić, D., Osmak, M., Šprem, M., and Abramić, M. (2003). Tumor cytosol dipeptidyl peptidase III activity is increased with histological aggressiveness of ovarian primary carcinomas. Gynecol. Oncol. 91, 194-200. 
Špoljarić, J., Salopek-Sondi, B., Makarević, J., Vukelić, B., Agić, D., Šimaga, Š., Jajčanin-Jozić, N., and Abramić, M. (2009). Absolutely conserved tryptophan in M49 family of peptidases contributes to catalysis and binding of competitive inhibitors. Bioorg. Chem. 37, 70-76.

Špoljarić, J., Tomić, A., Vukelić, B., Salopek-Sondi, B., Agić, D., Tomić, S., and Abramić, M. (2011). Human dipeptidyl peptidase III: the role of Asn406 in ligand binding and hydrolysis. Croat. Chem. Acta 84, 259-268.
Vukelić, B., Salopek-Sondi, B., Špoljarić, J., Sabljić, I., Meštrović, N., Agić, D., and Abramić, M. (2012). Reactive cysteine in the active-site motif of Bacteroides thetaiotaomicron dipeptidyl peptidase III is a regulatory residue for enzyme activity. Biol. Chem. 393, 37-46.

Zhang, H., Yamamoto, Y., Shumiya, S., Kunimatsu, M., Nishi, K., Ohkubo, I., and Kani, K. (2001). Peptidases play an important role in cataractogenesis: an immunohistochemical study on lenses derived from Shumiya cataract rats. Histochem. J. 33, 511-521. 